\title{
BLENDA POLIMÉRICA DE POLINDENO SULFONADO/POLIFLUORETO DE VINILIDENO PARA APLICAÇÃO COMO ELETRÓLITO EM CÉLULAS A COMBUSTÍVEL*
}

\author{
Raquel Dei Agnoli ${ }^{1}$ \\ Maurício Azevedo de Freitas ${ }^{2}$ \\ Tomás Ferreira Leão ${ }^{3}$ \\ Rejane Kraemer Kirchner ${ }^{4}$ \\ Mariska Hattenberg ${ }^{5}$ \\ Maria Madalena de Camargo Forte ${ }^{6}$
}

\section{Resumo}

Membranas a base de polímeros perfluorosulfonados, como o Nafion ${ }^{\circledR}$ (DuPont), vêm sendo extensivamente usadas como membrana de troca protônica em células a combustível. Contudo, o elevado custo e a baixa condutividade em temperaturas superiores a $80^{\circ} \mathrm{C}$ restringem o uso destes dispositivos. Em opção ao uso da membrana Nafion ${ }^{\circledR}$, membranas a base da blenda polindeno sulfonado/polifluoreto de vinilideno (SPInd/PVDF) foram desenvolvidas, investigando 0 efeito da composição na performance das membranas. As membranas foram produzidas por evaporação de solvente da solução dos polímeros precursores. As blendas foram caracterizadas por termogravimetria e calorimetria exploratória diferencial. A caracterização das membranas eletrólito envolveu medidas de grau de inchamento, capacidade de troca iônica e condutividade protônica. Foi possível observar que o PVDF confere boa resistência mecânica e aumento da estabilidade térmica das membranas. Membrana com $50 \%$ em peso de PVDF apresentou a maior condutividade protônica $\left(1,89.10^{-3} \mathrm{~S} . \mathrm{cm}^{-}\right.$ 1). Membranas de SPInd reforçadas com PVDF mostraram resultados promissores para uso como eletrólito em células a combustível.

Palavras-chave: Célula a combustível; Polindeno sulfonado; Polifluoreto de vinilideno; membrana eletrólito

\section{SULFONATED POLY(INDENE)/ POLY(VINYLIDENE FLUORIDE) POLYMERIC BLEND FOR APPLICATION AS ELECTROLYTE IN FUEL CELLS}

\section{Abstract}

Perfluorosulfonic acid ionomer membranes, e.g. Nafion® (DuPont), have been extensively used as proton exchange membranes in PEMFCs due to their high proton conductivity and good mechanical properties. The drawbacks of Nafion $\AA$ membranes are the low proton conductivity and chemical stability at temperatures higher than $80^{\circ} \mathrm{C}$. The aim of this work was to blend SPInd with poly(vinylidene fluoride) (PVDF), a thermally stable fluorinated polymer, to obtain PEMs with good proton conductivity and mechanical integrity. The membranes were evaluated by thermogravimetric analysis, ion exchange capacity, water uptake and proton conductivity. It was found that a blended membrane with 50 wt\% PVDF had the highest proton conductivity of $1.89 .10^{-3} \mathrm{~S}_{\mathrm{cm}} \mathrm{cm}^{-1}$. This indicates that the PVDF reinforced SPInd membranes, offer possible improvement to Nafion® since it has a lower cost.

Keywords: Fuel cell; Polyindene; Polyvinylidene fluoride; Electrolyte membrane.

1 Eng. de Materiais, aluno de Mestrado, Laboratório de Materiais Poliméricos, Depto. de Materiais/Escola de Engenharia, Universidade Federal do Rio Grande do Sul (UFRGS), Porto Alegre, RS, Brasil.

2 Engenheiro de Materiais, aluno de Mestrado, Laboratório de Materiais Poliméricos, Departamento de Materiais/Escola de Engenharia, UFRGS, Porto Alegre, RS, Brasil.

3 Aluno de Graduação em Engenharia de Materiais, bolsista de Iniciação Científica, Laboratório de Materiais Poliméricos, Depto. de Materiais/Escola de Engenharia, UFRGS, Porto Alegre, RS, Brasil.

4 Física/UPF, aluna de Graduação em Eng. de Materiais, bolsista de Iniciação Científica, Laboratório de Materiais Poliméricos, Depto. de Materiais/Escola de Engenharia, UFRGS, Porto Alegre, RS, Brasil.

5 Química, bolsista de Atração de Jovens Talentos/CNPq, Laboratório de Materiais Poliméricos, Departamento de Materiais/Escola de Engenharia, UFRGS, Porto Alegre, RS, Brasil.

6 Química, Doutora em Ciências, Professora titular, Laboratório de Materiais Poliméricos, Departamento de Materiais/Escola de Engenharia, UFRGS, Porto Alegre, RS, Brasil. 


\section{INTRODUÇÃO}

Células a combustível de membrana polimérica (PEMFCs) vêm sendo consideradas uma alternativa promissora aos tradicionais motores a combustão, devido a elevada eficiência elétrica, baixa emissão de gases causadores do efeito estufa e baixa temperatura de operação. A membrana polimérica é um dos componentes chave da PEMFC, pois, além de separar os eletrodos, age como barreira a passagem de combustíveis e é responsável pelo transporte dos prótons do ânodo para o cátodo (1). Membranas baseadas em polímeros perfluorosulfônicos, como a Nafion ${ }^{\circledR}$ (DuPont) são intensamente utilizadas como membranas trocadoras de próton (PEMs) em PEMFCs devido ao seu excelente balanço de propriedades como elevada condutividade protônica e boas propriedades mecânicas. Como desvantagens, a Nafion ${ }^{\circledR}$ apresenta baixas condutividade protônica e estabilidade química em temperaturas acima de $80^{\circ} \mathrm{C}$, devido à desidratação.

Polímeros hidrocarbônicos que, quando comparados com a Nafion ${ }^{\circledR}$, apresentam alta estabilidade térmica e condutividade protônica, têm sido desenvolvidos para utilização como eletrólito polimérico. Dentre os polímeros estudados está a classe de polímeros aromáticos como poli(éter-éter-cetona) (PEEK) e poli(ftalazinona éter cetona) (PPEK) sulfonados que são comercializadas (FumaTech), polibenzimidazol dopado com $\mathrm{H}_{3} \mathrm{PO}_{4}$, geralmente utilizado como eletrólito para células a combustível de alta temperatura (3) e polisulfona sulfonada que, quando dopada com ácido fósfomolibdico, é uma candidato promissor para aplicações em PEMFC (4).

Em trabalho prévio, Brum e colab. (5) reportaram que polindeno sulfonado (SPInd) no estado sólido apresenta condutividade iônica na temperatura ambiente da mesma ordem de grandeza que a Nafion ${ }^{\circledR}\left(10^{-2} \mathrm{~S} . \mathrm{cm}^{-1}\right)$. A temperatura de degradação dos grupos sulfônicos $\left(-\mathrm{SO}_{3} \mathrm{H}\right)$ e temperatura de transição vítrea ocorre acima de $200^{\circ} \mathrm{C}$, tornando o polímero adequado para uso como eletrólito em PEMFC. No entanto, a baixa massa molar do PInd impede a produção de membranas com integridade física suficiente para aplicação como eletrólito. Este trabalho tem por objetivo produzir blendas poliméricas de SPInd com polifluoreto de vinilideno (PVDF), a fim de produzir PEMs com boa resistência mecânica, estabilidade térmica e boa condutividade protônica.

\section{MATERIAIS E MÉTODOS}

\subsection{Materiais}

Polindeno sulfonado (SPInd), grau de sulfonação de $31 \mathrm{~mol} \%$, obtido conforme Brum e colab. (5); Poli(fluoreto de vinilideno) (PVDF/Kinar ${ }^{\circledast}$ MG15), com percentual de cristalinidade de $57 \%$, doado pela empresa Arkema; membranas Nafion ${ }^{\circledR}-117$ (DuPont); N,N-dimetilformamida (DMF; PA), ácido sulfúrico (98\% PA), peróxido de hidrogênio (PA) hidróxido de sódio (PA) e cloreto de sódio (PA), adquiridos no mercado local.

\subsection{Preparação e ativação das membranas}

As membranas foram produzidas a partir de blendas poliméricas por processo de vazamento ou casting, conforme Figura 1. Os componentes poliméricos no total de 1 grama, foram solubilizados em $20 \mathrm{~mL}$ de dimetilformamida (DMF). As soluções foram mantidas sob agitação por 24 horas em temperatura ambiente e vertidas em 
placas de Petri. A evaporação do solvente foi feita em estufa à $80{ }^{\circ} \mathrm{C}$ por 18 horas. $\mathrm{A}$ proporção de SPInd na blenda com PVDF em razão mássica foi de 50\%, 33\%, 25\% ou $16 \%$.

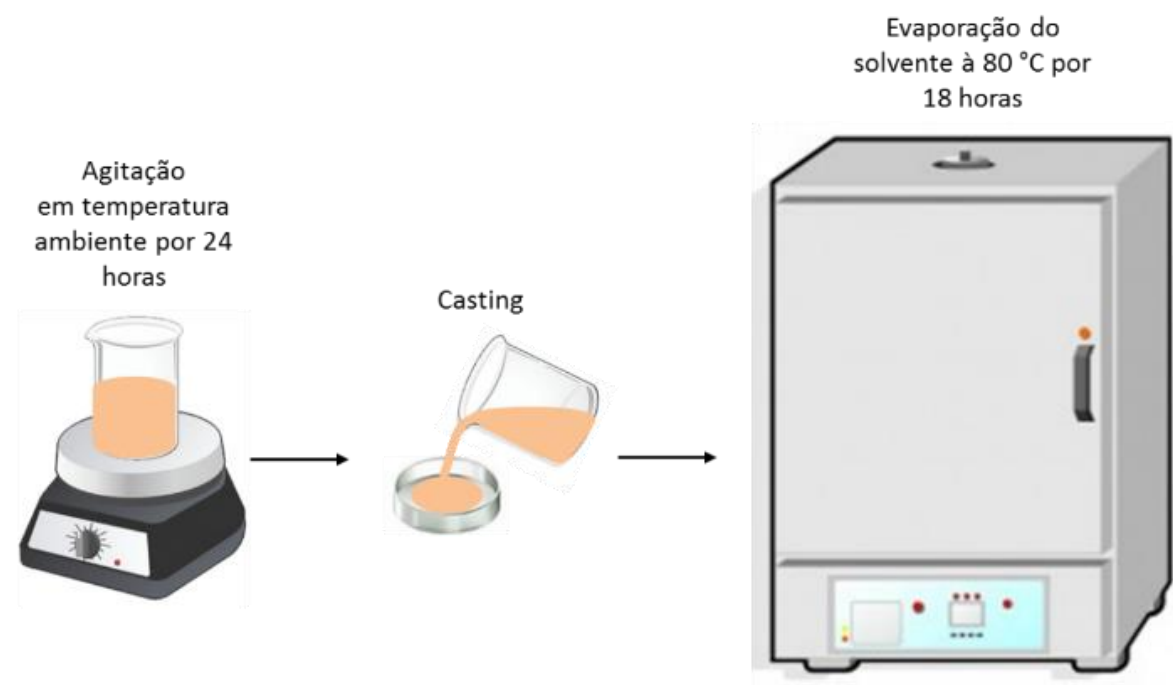

Figura 1. Esquema da preparação das membranas SPInd/PVDF.

A ativação das membranas foi feita em solução de $\mathrm{H}_{2} \mathrm{SO}_{4}(5 \%)$ à $80^{\circ} \mathrm{C}$ durante 1 hora, sendo em seguida, lavadas por imersão em água deionizada à $80{ }^{\circ} \mathrm{C}$, repetidas vezes até a água do banho atingir $\mathrm{pH}$ 7. As membranas ativadas foram mantidas em água deionizada até serem utilizadas.

A membrana Nafion ${ }^{\circledR}$ utilizada para comparação, foi ativada por imersão, estas foram primeiramente imersas em $\mathrm{H}_{2} \mathrm{O}_{2}(3 \%)$ a $80{ }^{\circ} \mathrm{C}$ durante 30 min, para remoção de quaisquer impurezas orgânicas. Em seguida, as membranas foram lavadas em água deionizada à $80^{\circ} \mathrm{C}$ por 30 min (três lavagens). $\mathrm{O}$ processo de ativação em $\mathrm{H}_{2} \mathrm{SO}_{4}$ foi o mesmo das blendas SPInd/PVDF.

\subsection{Caracterização das membranas}

Os polímeros precursores e blendas poliméricas foram avaliados termogravimetria em uma balança termogravimétrica TGA 2050 (TA Instruments) e por calorimetria em um DSC Q20 (TA Instruments). No TGA, as amostras foram aquecidas da temperatura ambiente até $800{ }^{\circ} \mathrm{C}$ sob taxa de aquecimento de $20^{\circ} \mathrm{C} / \mathrm{min}$, em atmosfera de nitrogênio, e no DSC, foram aquecidas de $-80^{\circ} \mathrm{C}$ à $380^{\circ} \mathrm{C}$ sob taxa de aquecimento de $10^{\circ} \mathrm{C} / \mathrm{min}$. A partir da área do pico de fusão dos termogramas de DSC foi calculada a entalpia de fusão do PVDF puro e na blenda com SPInd. A comparação com a entalpia de fusão padrão do PVDF forneceu o teor de cristalinidade segundo a Equação 1:

$$
\% \text { cristalinidade }=\frac{\Delta H f}{\Delta H f^{\circ}} * 100
$$

Onde $\Delta \mathrm{H}_{\mathrm{f}}$ corresponde a entalpia de fusão do polímero semicristalino e $\Delta \mathrm{H}_{\mathrm{f}}{ }^{\circ}$ a entalpia de fusão do polímero teórico $100 \%$ cristalino. Para o cálculo do teor de cristalinidade das blendas foi feita uma ponderação relativa a mistura com um polímero amorfo. 
O grau de inchamento (WU) foi determinado pelo monitoramento da variação da massa. As membranas foram secas em estufa à $80^{\circ} \mathrm{C}$ por 24 horas até peso constante. As membranas secas foram pesadas (Mseca) e imersas em água deionizada à $80{ }^{\circ} \mathrm{C}$ por 24 horas. $\mathrm{O}$ excesso de água adsorvida a superfície das membranas foi removido com papel e estas foram imediatamente pesadas (Múmida). O grau de inchamento foi calculado pela Equação 2:

$$
\boldsymbol{W U}(\%)=\frac{M_{\text {úmida }}-M_{\text {seca }}}{M_{\text {seca }}} * 100
$$

A determinação da capacidade de troca iônica (IEC) das membranas foi feita por titulação de neutralização utilizando fenolftaleína como indicador. Após secagem à $80{ }^{\circ} \mathrm{C}$ por 24 horas até peso constante (Mseca), as membranas foram imersas em solução de $\mathrm{H}_{2} \mathrm{SO}_{4}(0,5 \mathrm{~mol} / \mathrm{L})$ por 24 horas, para protonação dos grupos sulfônicos. As amostras foram lavadas com água deionizada, secas e imersas em solução de $\mathrm{NaCl} 2 \mathrm{M}$ a temperatura ambiente por 24 horas, para substituição dos prótons dos grupos sulfônicos por íons $\mathrm{Na}^{+}$, conforme procedimento explicitado no esquema da Figura 2.

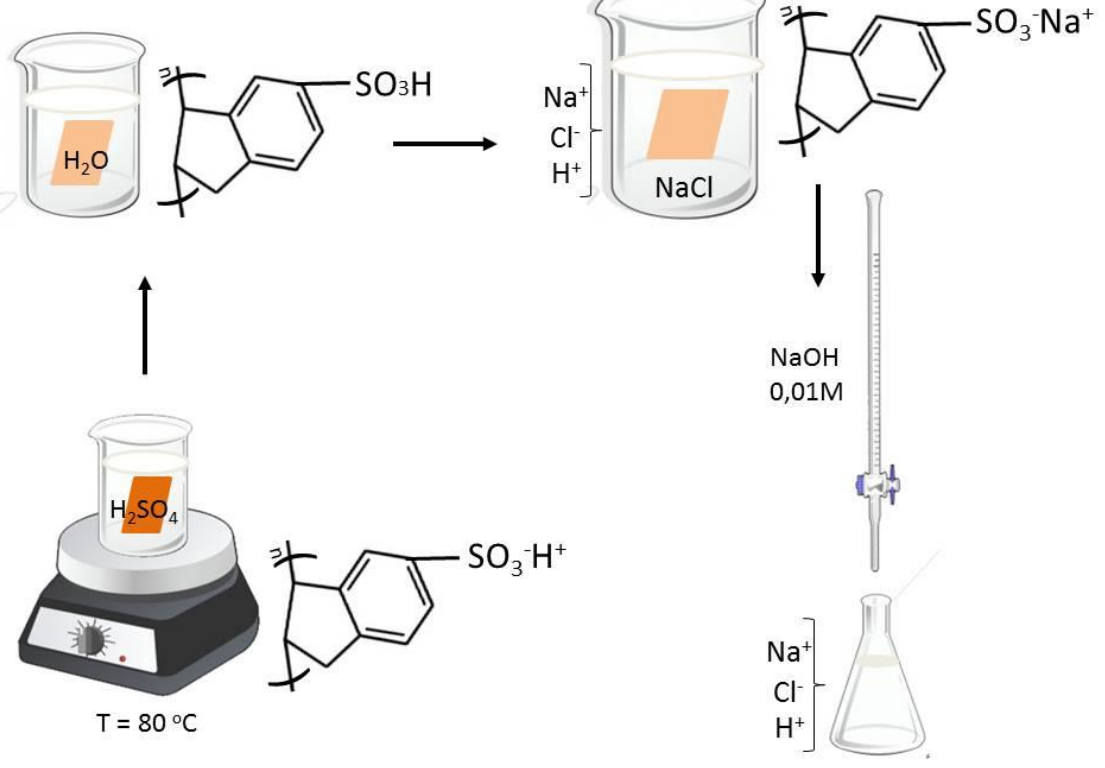

Figura 2. Esquema figurativo da análise de IEC das membranas SPInd/PVDF.

A solução de $\mathrm{NaCl}$ contendo a membrana imersa com $\mathrm{NaOH} 0,01 \mathrm{~mol} / \mathrm{L}$. Os valores de IEC foram calculados segundo a Equação 3, onde $\mathrm{V}_{\mathrm{NaOH}}$ e $\mathrm{CNaOH}$ são o volume e a concentração de titulante, respectivamente:

$$
I E C=\frac{V_{\mathrm{NaOH} * C_{\mathrm{NaOH}}}}{M_{\mathrm{seca}}}
$$

A condutividade protônica transversal das membranas foi determinada por espectroscopia de impedância eletroquímica (EIS) em um potenciostato Novocontrol modelo Alpha A em frequências entre $10^{-2}-10^{7} \mathrm{~Hz}$ e corrente alternada de $0.1 \mathrm{~V}$. As medidas foram realizadas a temperatura e umidade relativa ambiente, em porta 
amostra de PTFE e eletrodos de aço inox de $15 \mathrm{~mm}$ de diâmetro, conforme desenho esquemático mostrado na Figura 3.

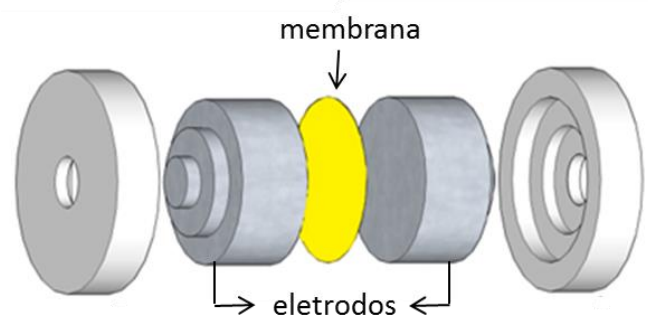

Figura 3. Desenho esquemático do porta amostra para medida de impedância.

\section{RESULTADOS E DISCUSSÃO}

PVDF é um homopolímero semicristalino, e foi utilizado na blenda com SPInd em teores de até $50 \%$. Membranas com teores de SPInd superiores, quando imersas em água deionizada, apresentaram comportamento instável, sendo observada a lixiviação do polímero eletrólito. A migração do polímero eletrólito para a solução se deve ao fato do SPInd formar domínios dispersos na fração amorfa do polímero fluorado, e teores de SPInd acima de $50 \mathrm{wt} \%$ saturam o volume livre da fração amorfa. As membranas com teor de SPInd inferior a 50\% apresentaram-se homogêneas, de cor amarela, flexíveis e com resistência mecânica suficiente para o manuseio durante todos os ensaios.

\subsection{Comportamento térmico}

A Figura 4 apresenta os termogramas de TGA do PVDF e SPInd com grau de sulfonação de $31 \%$. Verifica-se que o PVDF apresenta um único evento de decomposição em $460^{\circ} \mathrm{C}$ e teor de resíduo de $27,4 \%$. O alto teor de resíduo se deve a carbonização da cadeia principal em virtude da liberação concomitante de ácido fluorídrico. O PVDF é um polímero estável química e termicamente, devido à presença de átomos de flúor na cadeia principal e à alta energia da ligação $C-F(6)$. Por outro lado, o SPInd apresenta três eventos de perdas de massa (Fig. 4b), sendo o primeiro $\left(\mathrm{T}<100{ }^{\circ} \mathrm{C}\right)$ relativo à perda de água, em virtude de ser um polímero hidrofílico. A segunda perda de massa à $299^{\circ} \mathrm{C}$ é devido a decomposição dos grupos $-\mathrm{SO}_{3} \mathrm{H}$, e o terceiro evento térmico à $353^{\circ} \mathrm{C}$ se deve a degradação da cadeia principal. $\mathrm{O}$ alto resíduo de $17,5 \%$, se deve a concomitante ciclização e carbonização dos anéis aromáticos e ciclopenteno durante a degradação da cadeia, uma vez que a análise foi realizada em atmosfera de nitrogênio. Polímeros com cadeia formada com anéis aromáticos ou estrutura cíclica, devido à alta estabilidade térmica tendem a carbonizar. 

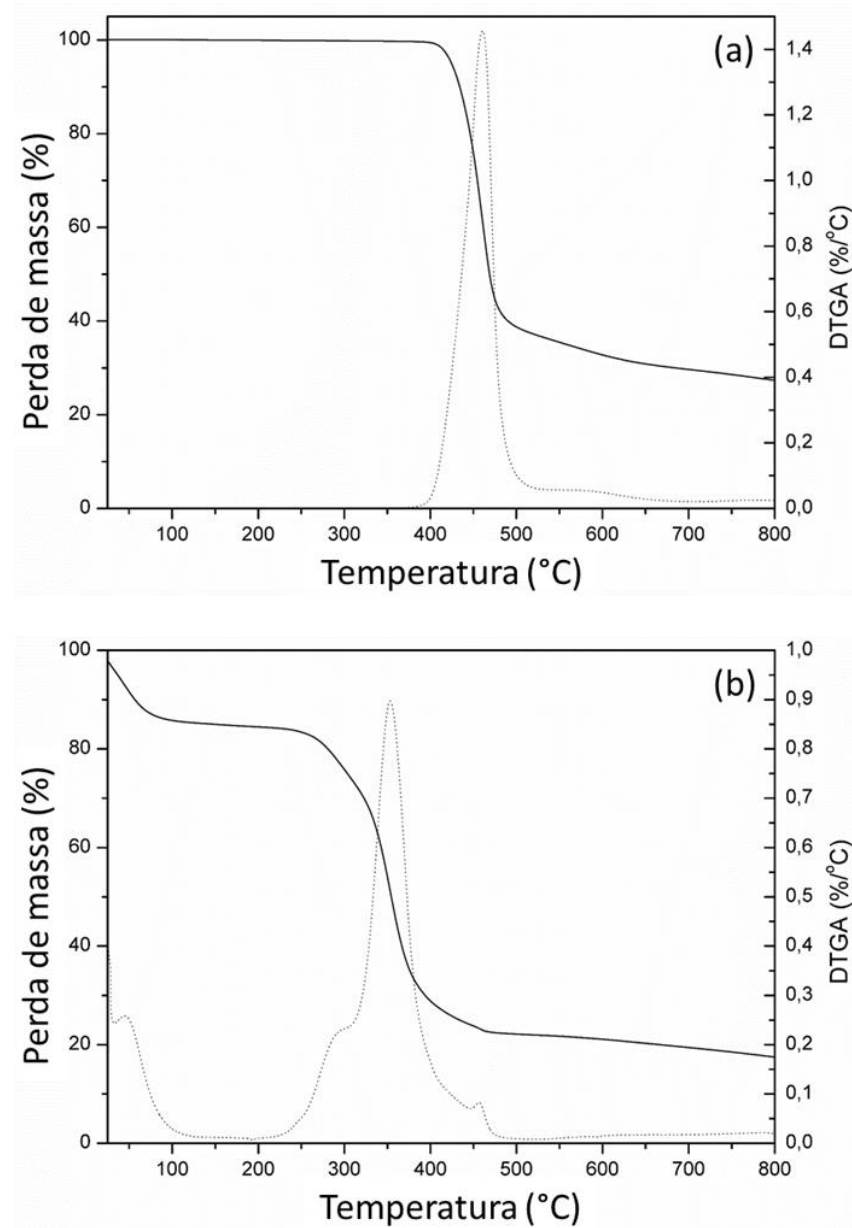

Figura 4. Termogramas de TGA dos polímeros precursores. (a) PVDF e (b) SPInd.

A Figura 5 apresenta o termograma de TGA da blenda 50-SPInd/PVDF e o tipo de interação química possível de ocorrer entre os heteroátomos, ilustrados na unidade repetitiva dos polímeros. A primeira perda de massa, abaixo de $200^{\circ} \mathrm{C}$, pode ser atribuída a perda de água ligada aos grupos $-\mathrm{SO}_{3} \mathrm{H}$ e resquícios de solvente. $\mathrm{O}$ evento em $368{ }^{\circ} \mathrm{C}$ pode ser atribuído a decomposição dos grupos $-\mathrm{SO}_{3} \mathrm{H}$, concomitante com a degradação da cadeia principal do SPInd. Devido a presença de PVDF, estas degradações ocorrem em temperatura levemente superior aos dois eventos observados para o SPInd puro. A terceira perda de massa, em $467^{\circ} \mathrm{C}$, cuja derivada apresenta um pico bimodal que caracteriza a saída de dois componentes com estruturas distinta, é devido a decomposição do PVDF que sofre interferência quando na presença do SPInd. Os eventos de degradação da blenda com 50wt\% SPInd ocorreram em temperaturas superiores aos eventos observados no polímero puro, o que pode ser atribuído à interação dos átomos de flúor do PVDF com os hidrogênios ácidos dos grupos $-\mathrm{SO}_{3} \mathrm{H}$ (Fig. 5b). A formação de ligações de hidrogênio estabilizam os grupos sulfônicos, retardando tanto a decomposição dos grupos, quanto a degradação da cadeia do polímero eletrólito. O resíduo a $800^{\circ} \mathrm{C}$ de $22,5 \%$ está compatível com a composição da blenda e resulta da alta estabilidade térmica de ambos polímeros. As membranas eletrólito em uma PEMFC estão expostas a um ambiente oxidante e a alta temperatura $\left(80\right.$ a $\left.120^{\circ} \mathrm{C}\right)$ durante longos períodos de operação (1), devendo apresentar estabilidade térmica e química. 

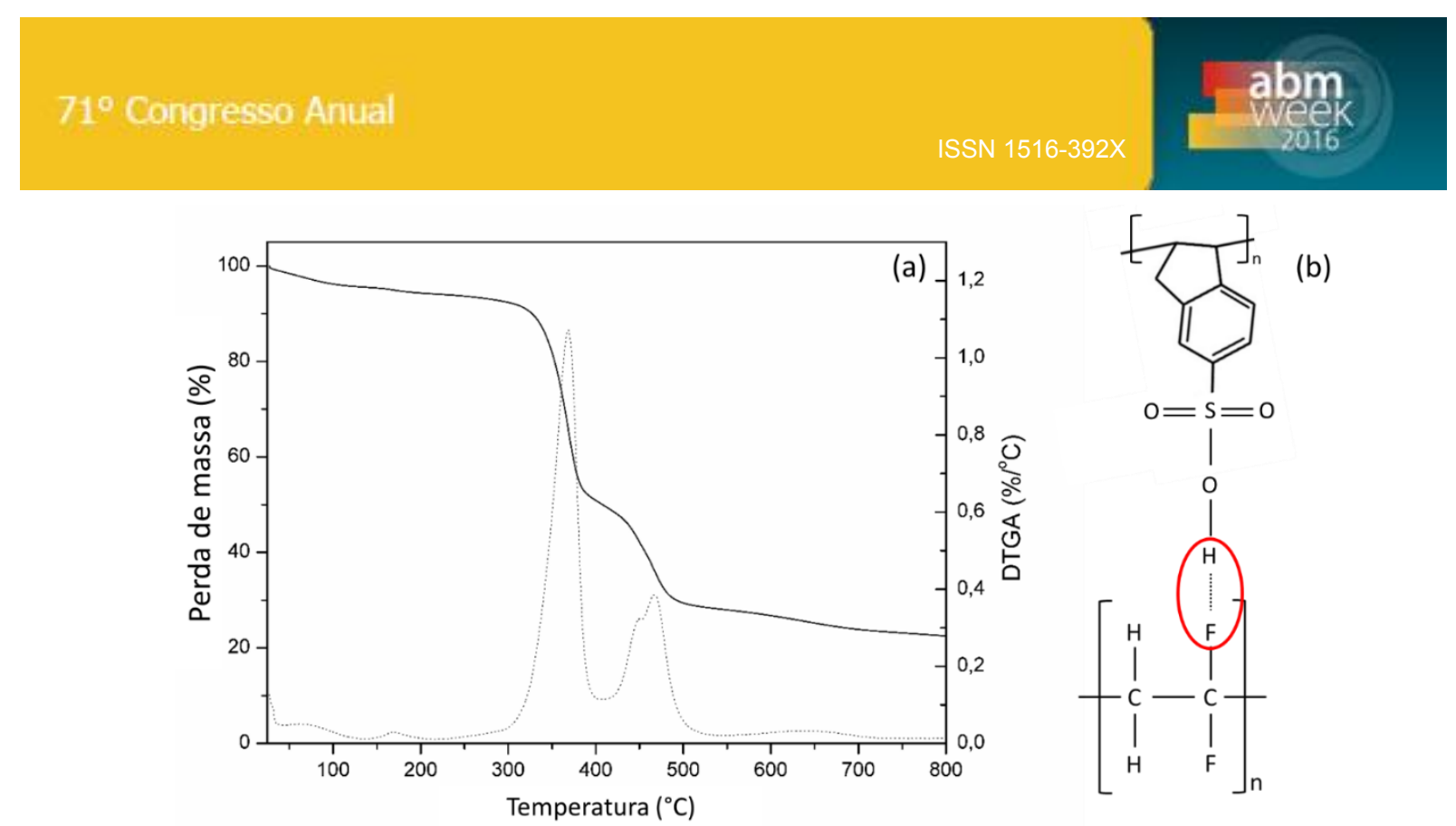

(b)

Figura 5. (a) Termograma de TGA da blenda 50-SPInd/PVDF e (b) esquema tipo de ligação de hidrogênio entre o SPInd e o PVDF nas membranas.

Observou-se pelos termogramas de DSC do PVDF e da blenda com $50 \%$ de SPInd que ocorreu redução da cristalinidade do PVDF que, na membrana, foi de $39 \%$. A condutividade de prótons ocorre na fração amorfa da membrana (7) a qual é constituída pela fração amorfa do PVDF na qual o SPInd está disperso.

\subsection{Propriedade das membranas SPInd/PVDF}

A capacidade de troca iônica e o grau de inchamento das membranas SPInd/PVDF foram avaliadas comparativamente a Nafion ${ }^{\circledR}-117$. Estas duas características estão relacionadas com a quantidade de grupos trocadores de prótons presentes no eletrólito (8) que, por sua vez, determinam a capacidade de condução protônica da membrana. A Tabela 1 apresenta os valores de grau de inchamento (WU) à $80^{\circ} \mathrm{C}$ e a capacidade de troca iônica (IEC) das membranas SPInd/PVDF com diferentes teores do polímero eletrólito. Observou-se aumento dos valores de WU e IEC com o aumento da quantidade de SPInd na blenda, o que se deve ao aumento da quantidade de grupos $-\mathrm{SO}_{3} \mathrm{H}$, os quais favorecem absorção de água e intensificam a troca iônica, devido à alta hidrofilicidade destes grupos.

Tabela 1. Grau de inchamento (WU) e capacidade de troca iônica (IEC) das membranas SPInd/PVDF

\begin{tabular}{l|c|c|c|c|c}
\hline \multirow{2}{*}{ Membrana } & \multicolumn{4}{|c|}{ SPInd/PVDF } & \multirow{2}{*}{ Nafion $^{\circledR}$} \\
\cline { 2 - 5 } & $\mathbf{1 6 \%}$ & $\mathbf{2 5 \%}$ & $\mathbf{3 3 \%}$ & $\mathbf{5 0 \%}$ & \\
\hline Espessura $(\boldsymbol{\mu m})$ & 175 & 184 & 250 & 236 & 183 \\
\hline WU (\%) & 6,15 & 11,05 & 18,23 & 42,3 & 26 \\
\hline IEC (mmol/g) & 0,36 & 0,64 & 0,85 & 1,27 & 0,73 \\
\hline
\end{tabular}

A condutividade protônica dos eletrólitos poliméricos depende da quantidade de componentes que podem se dissociar em espécies iônicas, no caso grupos $-\mathrm{SO}_{3} \mathrm{H}$, e da formação de canais hidrofílicos de condução interconectados (9). A Figura 6 mostra os valores de condutividade protônica das membranas, que mantiveram a mesma tendência das medidas de IEC e WU. 

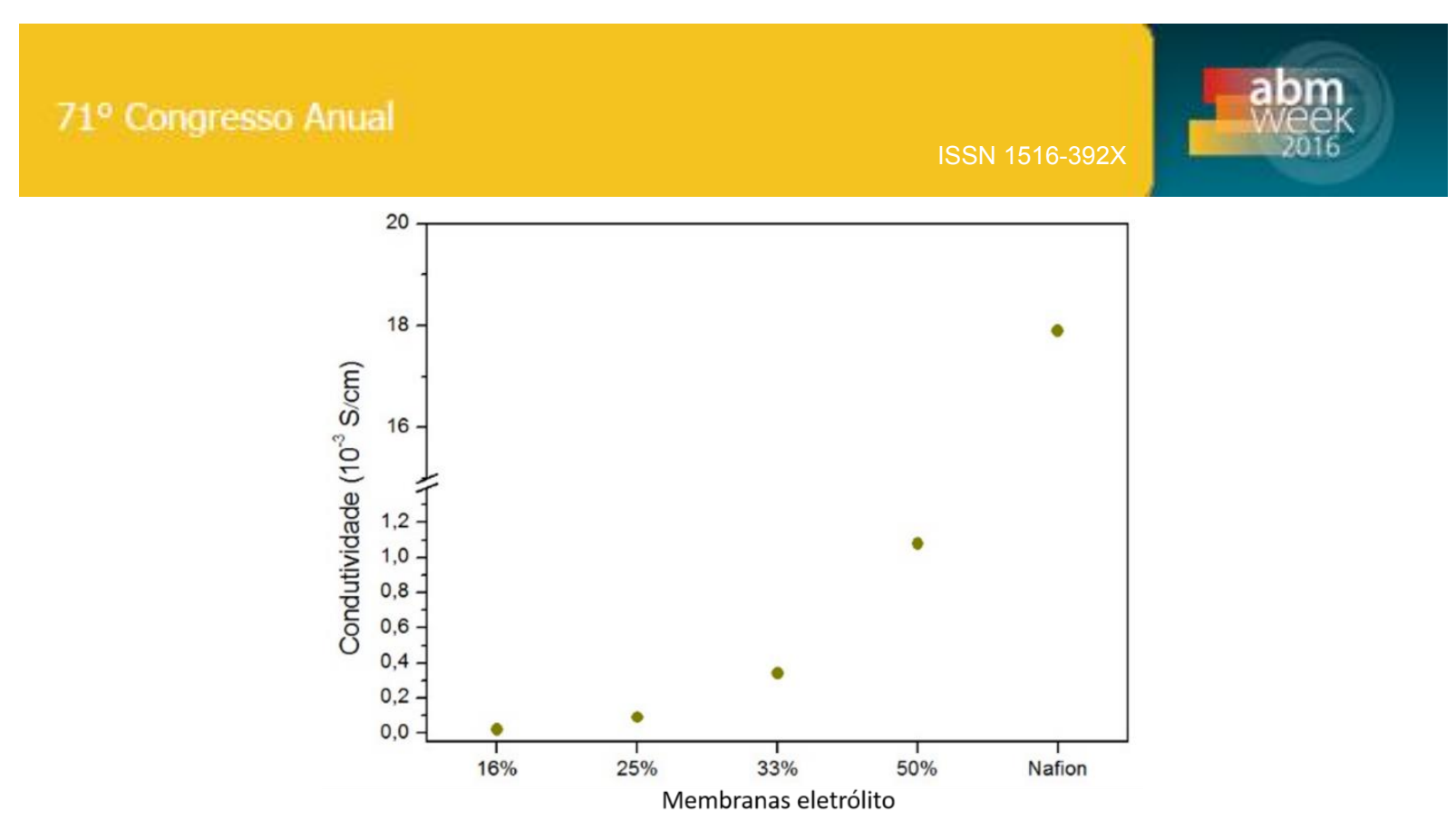

Figura 6. Condutividade das membranas.

A membrana eletrólito com maior condutividade foi a membrana 50-SPInd/PVDF, sendo esta de $1,08.10^{-3} \mathrm{~S} / \mathrm{cm}$, inferior ao valor determinado para a Nafion ${ }^{\circledR}$ de $1,78.10^{-2} \mathrm{~S} / \mathrm{cm}$, analisada sob as mesmas condições. Apesar dos valores de IEC e WU da membrana 50-SPInd/PVDF serem superior aos determinados para a Nafion, a condutividade da membrana Nafion foi maior, que pode ser atribuído a diferença morfológica entre as membranas. A membrana Nafion ${ }^{\circledR}$ apresenta domínios interconectados formados por canais hidrofílicos contendo cadeias laterais com terminação $-\mathrm{SO}_{3} \mathrm{H}$, distribuídos em uma matriz fluorada hidrofóbica amorfa. Em contraste, as membranas de SPInd/PVDF possuem canais hidrofílicos formados por grupos $-\mathrm{SO}_{3} \mathrm{H}$ ligados a anéis aromáticos di-substituídos conectados lateralmente a cadeia principal do polímero, dispersos em uma matriz hidrocarbônica apolar contida na fase amorfa fluorada do PVDF. Esta composição heterofásica, (fases hidrofílicas e hidrofóbicas), afeta a morfologia dos canais hidrofílicos, podendo restringir a condutividade protônica.

\section{CONCLUSÃo}

Membranas de SPInd/PVDF de troca protônica, com diferentes composições do polímero eletrólito, foram obtidas por vazamento (casting) da solução destes em DMF. A blenda que apresentou melhores resultados de WU, IEC e condutividade iônica foi aquela com $50 \%$ de SPInd (50-SPInd/PVDF), devido ao maior teor de grupos sulfônicos, responsáveis pela troca de íons. A interação intermolecular entre os polímeros precursores, ou as ligações de hidrogênio entre os átomos de flúor do PVDF e hidrogênios ácidos dos grupos sulfônicos do SPInd, pode ser evidenciada pela maior estabilidade térmica das membranas em relação ao SPInd puro. De acordo com os resultados preliminares, as membranas de SPInd/PVDF apresentam potencial para uso como polímero eletrólito em PEMFC. Uma forma mais eficiente de preparação das membranas SPInd/PVDF está sendo avaliada, as quais, futuramente, serão testadas quanto a estabilidade química e mecânica, e avaliadas em protótipo de PEMFC alimentada com hidrogênio. 


\section{Agradecimentos}

Os autores agradecem a Coordenação Nacional de Pesquisa (CNPq) e a Financiadora de Estudos e Projetos (Finep) pelo auxílio financeiro recebido, e ao Prof. Rero Rubinger (UNIFEI) pelo auxílio e discussão de medidas de impedância eletroquímica.

\section{REFERÊNCIAS}

1. Wang J-L, Wang L-L, Feng R, Zhang Y. Synthesis and characterization of novel anion exchange membranes containing bi-imidazolium-based ionic liquid for alkaline fuel cells. Solid State lonics. 2015; 278:144-51.

2. Marczynski, ES. Avaliação de membranas hidrocarbônicas não fluoradas para uso como eletrólito em célula a combustível tipo DEFC. Dissertação de mestrado (PPGE3M-UFRGS). 2013.

3. Chandan A, Hattenberger M, El-kharouf A, Du S, Dhir A, Self V, et al. High temperature (HT) polymer electrolyte membrane fuel cells (PEMFC) - A review. J Power Sources. 2013; 231:264-78.

4. Martínez-Morlanes MJ, Martos a. M, Várez a., Levenfeld B. Synthesis and characterization of novel hybrid polysulfone/silica membranes doped with phosphomolybdic acid for fuel cell applications. J Memb Sci. 2015; 492:371-9.

5. Brum FJB, Zanatta FG, Marczynski ES, Forte MMC, Pollet B. Synthesis and characterisation of a new sulphonated hydrocarbon polymer for application as a solid proton-conducting electrolyte. Solid State lonics. 2014; 263:62-70.

6. Cui Z, Drioli E, Lee YM. Recent progress in fluoropolymers for membranes. Prog Polym Sci. 2014; 39:164-98.

7. Muthuvinayagam $\mathrm{M}$, Gopinathan $\mathrm{C}$. Characterization of proton conducting polymer blend electrolytes based on PVdF-PVA. Polymer. 2015; 68:122-30.

8. Ahmadian-Alam L, Kheirmand M, Mahdavi H. Preparation, characterization and properties of PVDF-g-PAMPS/PMMA-co-PAMPS/silica nanoparticle as a new proton exchange nanocomposite membrane. Chem Eng J. 2016; 284:1035-48.

9. Mondal S, Soam S, Kundu PP. Reduction of methanol crossover and improved electrical efficiency in direct methanol fuel cell by the formation of a thin layer on Nafion 117 membrane: Effect of dip-coating of a blend of sulphonated PVdF-co-HFP and PBI. J Memb Sci. 2015; 474:140-7. 